\title{
Recent epidemiological studies on boron exposure - contradiction between hazard and risk-based
} assessments

\section{Introduction}

Boric acid and inorganic borates are abundant in nature and widely used in industrial, agricultural, cosmetic and many different applications since a long time. ${ }^{1}$ Accordingly, large populations are exposed to certain levels of boron due to these applications and especially from drinking water. Boron concentrations in drinking waters show enormous differences across the world. For example in a study conducted by Yazbeck et al., in Northern France reported boron concentration around $0.3 \mathrm{mg} \mathrm{B} / \mathrm{L}$ in drinking water. However, studies in Bigadicregion of Turkey ${ }^{3}$ and Arica of Chile 4 reported extreme levels of boron in drinking watersamples (Bigadicregion: up to $29 \mathrm{mg}$ $\mathrm{B} / \mathrm{L}$ in some seasons, Arica: up to $11.3 \mathrm{mg} \mathrm{B} / \mathrm{L}$ ). These extreme levels are a natural consequence of boron deposits located around both areas. Therefore the total boron intake in daily life generally depends on the geographical area where people live. The total boron intake for humans varies between $1.7-7.0 \mathrm{mg} /$ day in the United States, 0.8 $1.9 \mathrm{mg} /$ day in the European Union and $2.16-2.28 \mathrm{mg}$ /day in Australia. ${ }^{5}$ However, the daily intake of boron can be much higher in populations living around the boron rich areas as will be mentioned below.

\section{Hazard assessment of boric acid and inorganic borates}

Boric acid and inorganic borates are not genotoxic, mutagenic and carcinogenic. However high doses of boron administration exhibit reprotoxic effects in animal experiments. Boron mediated decreased sperm count and/or lack of viable sperm were reported in boron administered male rats and $17.5 \mathrm{mg} \mathrm{B} / \mathrm{kg}$ bw/day was identified as the NOAEL for these adverse effects. On the other hand decreased fetal body weight was reported in female rats treated with high level of boron. The NOAEL for this adverse effect was $9.6 \mathrm{mg} \mathrm{B} / \mathrm{kg}$ bw/ day. ${ }^{6}$ According to the above mentioned results in animal experiments (hazard assessment) boric acid and sodium borates are classified as toxic to reproduction under "Category 1B" with the hazard statement of "H360 FD" in the CLP Regulation (European Regulation on Classification, Labelling and Packaging of substances and mixtures). After this classification many boron containing products were stigmatized. Additionally, this classification played an important role in increasing public concern about reprotoxic effects of boron especially for the populations living around the boron deposits that lead to a high level of daily boron exposure. However, when this classification enters into force in 2007, an epidemiological study on boron exposure conducted in highly boron exposed cohort was not available.

\section{The results of the epidemiological studies}

\section{The results of the epidemiological study in China}

The study was conducted in boron mining and/or processing plant in Liaoning prvince of northeastern China., ${ }^{78}$ The mean daily boron

\author{
Volume 3 Issue 3 - 2017
}

\author{
Yalçin Duydu, Aylin Üstündag \\ Department of Toxicology, Ankara University, Turkey
}

Correspondence: Yalçin Duydu, Department of Toxicology, Ankara University, Faculty of Pharmacy, 06100 Ankara, Turkey, Email duydu@pharmacy.ankara.edu.tr

Received: June 21, 2017 | Published: July 05, 2017

exposure of the highly boron exposed group was reported as $37.0 \mathrm{mg} /$ day which reflects environmental plus occupational boron exposure. This level of boron exposure is much higher than the daily boron intake levels estimated for different developed countries as mentioned above. In spite of this high level of boron exposure, statistically significant differences in semen quality parameters between exposure and control groups were not reported. ${ }^{8}$ In a further study the total sperm counts, sperm concentration, sperm motility, sperm morphology and DNA damage in sperm cells were determined in a boron exposed worker group to investigate the possible correlation between these parameters and blood/urine boron concentrations. However statistically significant correlations between these parameters were not reported. ${ }^{9}$

\section{The results of the epidemiological study in Turkey}

The study was conducted in boron exposed male workers employed in Bandirma Boric Acid Production Plant in order to investigate boron mediated effects on reproductive toxicity indicators. The study group was exposed to boron via inhalation (occupational exposure) during their work shift and additionally by drinking water (environmental exposure). Boron concentration in the drinking water of the study area was $9.5 \mathrm{mg} / \mathrm{L}$. The workers were classified into control, low, medium and high exposed groups according to their blood boron concentrations. The calculated mean daily boron exposure was $14.45 \mathrm{mg}$ /day for the high exposure group. The reproductive toxicity parameters (FSH, LH, testosterone levels, DNA damage in sperm cells, sperm concentration, motility and morphology parameters) were compared between control and exposed groups. However, boron mediated unfavorable effects were not reported. Additionally, the correlations between blood/ urine boron concentrations and the above mentioned parameters were statistically not significant. ${ }^{10-14}$

\section{The results of the epidemiological study in Argentina}

Argentina have also some boron rich areas. In recent years some studies were conducted on boron exposure through drinking water in pregnant woman and the birth size in population living in the Andean part of the Salta province of northern Argentina (altitude 3180-4070m above sea level). ${ }^{15}$ Drinking water is reported as the major source of boron exposure (377-10929 $\mu \mathrm{g} \mathrm{B/L})$ for this Study area. The results of this study reported an inverse association between elevated boron 
exposure and birth size. This is the first and only epidemiological study that support the boron mediated decreased fetal bodyweight in boron exposed females. However, some major confounders have not been considered in interpreting the results of this study. The studied population co-exposed to boron and lithium at the same time. The authors reported an inverse association also between lithium exposure during pregnancy and fetal size in their earlier published study at the same sampling area. ${ }^{16}$ On the other hand, the study area is located $3180-4070 \mathrm{~m}$ above the sea level. There are many published studies on the relation between low birthweights and high altitude. ${ }^{17,18}$ In a study conducted in Colorado (970-3550m above the sea level) birth weight declined $121 \mathrm{~g}$ for every $1000 \mathrm{~m}$ gain when the effect of altitude was considered alone. However, the negative effect of the high altitude on the body weights of newborns has not been taken into account in the study published by Igra et al. ${ }^{15}$ Under the above mentioned circumstances the decreased birth size couldn't be attributed to the boron exposure.

\section{What did we learn from epidemiological studies?}

\section{Boron exposed males}

The recently published epidemiological studies reveal that daily boron intake can be much higher in some special geographic areas than the daily boron intake levels calculated for some developed countries. Extreme boron exposure levels were reported in both epidemiological studies in China and Turkey. These exposure levels were far above the daily boron intake levels for humans in daily life. However, unfavorable effects on sperm quality parameters were not reported in epidemiological studies in contrast to the animal experiments. In other words, hazard based assessment in male experimental animalsare not in line with the epidemiological studies in male workers even under worst case exposure conditions. On the other hand, the daily boron exposure levels provided by the epidemiological studies made it possible to perform risk based assessment for reprotoxic effects in men as shown below ${ }^{6,14}$

$\mathrm{RfD}_{\text {boron }}=\mathrm{NOAEL}_{\text {boron }} /$ UFboron (chemical specific uncertainty factor of boric acid $=60$ )

$$
\begin{aligned}
& \mathrm{RfD}_{\text {boron }}=17.5 / 60=0.29 \mathrm{mg} \mathrm{B} / \mathrm{kg}-\mathrm{bw} / \text { day } \\
& \mathrm{RfD}_{\text {boron }}=0.29 \times 70 \text { (average body weight of a man) } \\
& \mathrm{RfD}_{\text {boron }}=20.3 \mathrm{mg} \mathrm{B} / \text { day }
\end{aligned}
$$

Accordingly, the daily boron exposure lower than the RfDshould be safe for adult males and boron mediated reproductive toxicity shouldn't be expected. The mean daily boron exposure in the epidemiological study conducted in Turkey is lower (14.45mg B/day) than the RFD. Under these circumstances the lack of boron mediated reportoxic effects in male workers shouldn't be considered as a surprise. However the mean daily boron exposure reported in Chinese study (37.0mg B/day) is above the RFD calculated above. In spite of the reference dose of boron is being exceeded, reprotoxic effects have not been reported in Chinese study. From this point of view boron mediated reprotoxic effects does not seem possible for men under normal handling and use conditions in daily life.

\section{Boron exposed females}

Epidemiological studies on boron exposure in pregnant woman and the body weights of newborns in highly boron exposed areas are inadequate. Recently Igra et al., ${ }^{15}$ reported inverse association between boron exposure during pregnancy and birth size in northern Argentina. This study, however, shouldn't be considered as a supportive evidence for boron mediated developmental toxicity in females. As mentioned above lithium exposure and the high altitude of the sampling area have not been taken into consideration in that study. Therefore comprehensive epidemiological studies are needed especially on body weights of newborns in highly boron exposed populations.

\section{Conclusion}

Hazard identification is an early step in risk assessment and may offer benefit for regulatory decisions. However, hazard based classification and labelling of chemicals can be misunderstood and used to draw false conclusions about risk, without any consideration of potency or exposure. On the other hand, risk-based approaches provide practical information concerning the probable risk to the exposed population. ${ }^{19}$ The study conducted in Turkey provided daily exposure levels under worst case exposure conditions. ${ }^{1}$ Even under this exposure conditions boron mediated reprotoxic effects have not been reported. ${ }^{10-13}$ Additionally, boron mediated reprotoxic effects in male workers were not reported even in the Chinese study. The mean daily boron exposure level in this study was far above the RfD calculated above. Accordingly, risk assessment of boron in occupational settings reveal that boron mediated reprotoxic effects does not seem possible for men under normal handling and use conditions in daily life. Risk-based assessment for boron mediated developmental toxicity in females is unfortunately not possible in present time due to the lack of comprehensive epidemiological studies. Therefore, epidemiological studies on highly boron exposed females are strongly needed.

\section{Acknowledgements}

None.

\section{Conflict of interest}

The author declares no conflict of interest.

\section{References}

1. Bolt HM, Baseman N, Duydu Y. Human environmental and occupational exposures to boric acid: reconciliation with experimental reproductive toxicity data. J Toxicol Environ Health A. 2012;75(8-10):508-514.

2. Yazbeck C, Kloppmann W, Cottier R, et al. Health impact evaluation of boron in drinking water: a geographical risk assessment in Northern France. Environ Geochem Health. 2005;27(5-6):419-427.

3. Sayli BS. An assessment of fertility in boron-exposed Turkish subpopulations, 2. Evidence that boron has no effect on human reproduction. Biol Trace Elem Res. 1998;66(1-3):409-422.

4. Cortes S, Espinoza-Navarro O, Ferrecio C. High exposure to boron in drinking water and sperm parameters in Chilean young people. Int $J$ Morphol. 2017;35(1):99-104.

5. Pizzorno L. Nothing boring about boron. Integr Med. 2015;14(4):3547.

6. Duydu Y, Basaran N, Bolt HM. Risk Assessment of Borates in Occupational Settings. 1st ed. UK; 2015. p. 65-105.

7. Xing X, Wu G, Wei F, et al. Biomarkers of environmental and workplace boron exposure. J Occup Environ Hyg. 2008;5(3):141-147.

8. Scialli AR, Bonde JP, Brüske-Hohlfeld I, et al. An overview of male reproductive studies of boron with an emphasis on studies of highly exposed Chinese workers. Reprod Toxicol. 2010;29(1):10-24. 
9. Robbins WA, Xun L, Jia J, et al. Chronic boron exposure and human semen parameters. Reprod Toxicol. 2010;29(2):184-190.

10. Duydu Y, Basaran N, Ustundag A, et al. Reproductive toxicity parameters and biological monitoring in occupationally and environmentally boron-exposed persons in Bandirma, Turkey. Arch Toxicol. 2011;85(6):589-600.

11. Duydu Y, Basaran N, Ustundag A, et al. Assessment of DNA integrity (COMET assay) in sperm cells of boron-exposed workers. Arch Toxicol. 2012;86(1):27-35.

12. Duydu Y, Basaran N, Bolt HM. Exposure assessment of boron in Bandirma boric acid production plant. J Trace Elem Med Biol. 2012;26(2-3):161-164.

13. Basaran N, Duydu Y, Bolt HM. Reproductive toxicity in boron exposed workers in Bandirma, Turkey. J Trace Elem Med Biol. 2012;26(23):165-167.

14. Duydu Y, Basaran N, Ustundag A, et al. Is boric acid toxic to reproduction in humans? Assessment of the animal reproductive toxicity data and epidemiological study results. Curr Drug Deliv. 2016;13(3):324-329.
15. Igra AM, Harrari F, Lu Y, et al. Boron exposure though drinking water during pregnancy and birth size. Environ Int. 2016;95:54-60.

16. Harari F, Langeen M, Casimiro E, et al. Environmental exposure to lithium during pregnancy and fetal size: A longitudinal study in the Argentinean Andes. Environ Int. 2015;77:48-54.

17. Jensen M, Jensen MA, Lorna G Moore. The effect of high altitude and other risk factors on birthweight: Independent or Interactive effects? Am J Public Health. 1997;87(6):1003-1007.

18. Krampl E. Pregnancy at high altitude. Ultrasound Obstet Gynecol. 2002;19:535-539.

19. Barlow SM, Boobis AR, Bridges J, et al. The role of hazard- and riskbased approaches in ensuring food safety. Trends in Food Science and Technology. 2015;46(2):176-188. 